\title{
Immersed In Difficulty: The Problem of Suspension of Disbelief in Transmedia and Vr
} Experiences

\section{James Dalby, University of Gloucestershire, USA}

\begin{abstract}
.
The term Immersion is used widely in professional discourse and industry publications within the UK/US TV and film industries, not only as a self-evident aim of Transmedia and VR content, but also as an achievable goal. Unlike games industries, TV and cinema have traditionally taken the notion of Suspension of Disbelief (SoD) as relatively self-evident, and Immersion appears as its logical extension. Beginning with Holland's (1967) psychoanalytical approach to SoD as removal of the 'desire to act' function by 'framing' texts away from reality, this paper suggests that by including the 'frame' within the experience in Transmedia and VR, SoD is not achievable and therefore any attempts to approach Immersion in this way will fail. The paper argues that Immersion in such experiences is possible, if approached in the sense that Salen \& Zimmerman (2004) suggest, where the actual act of involvement becomes the immersive experience, and not the displacement of sense and story.
\end{abstract}


All forms of entertainment strive to create suspension of disbelief, a state in which the [...] mind forgets that it is being subjected to entertainment and instead accepts what it perceives as reality.

\section{François Dominic Laramée; 'Immersion'}

Broadcasters are planning to take viewers beyond traditional flat-screen viewing and tell stories in increasingly immersive ways in 2016.

\section{Alex Farber; ‘Broadcast Magazine’. January 2016}

We were interested in how we could make short-form drama more immersive and ideally help us to reach younger audiences. We wanted to up the levels of interaction, but not distract people from the story.

\section{Robin Moore; BBC Head of Innovation. May 2016}

In the last decade, a new lexicon of terminology and ideas that have previously been more generally associated with the computing and games industries, has been seen with increasing frequency in the discourse and industry publications of the UK and US television and film industries. In TV alone, programme-makers are now content-producers and programmes are asset-brands; multiplatform and multi-touchpoint in nature, and based around UX design concepts with developmental analytics, IP/API workflows and ' $3 \mathrm{G}$ ' commissioning just some of the ongoing computing-inspired hot-topics in the industry. In terms of contemporary content, one term stands out as becoming synonymous with film and TV industries' efforts to offer new audience-pleasing experiences, and also as a byproduct, synonymous with the technology being trialed to produce these experiences, such as Transmedia-technologies and Virtual Reality. This term is Immersion.

This paper argues that immersion within Transmedia and Virtual Reality experiences is a misleading concept, in need of interrogation and classification, and moreover that it is not possible to achieve, if the definition of immersion is taken to be similar to Laramée's quote above. This is to do with it being - in this form - the logical extension of the idea of suspension of disbelief, itself a term regularly treated as being somewhat self-evident in traditional television and film experiences. However, the paper also argues that immersion in Transmedia and VR content is possible, if approached in the sense that Salen \& Zimmerman 
(2004) suggest, where the actual act of involvement becomes the immersive experience, rather than the displacement of sense and story.

It is important at this stage to emphasise precisely what is being discussed concerning immersion and its relationship to TV and film experiences. The paper does not focus directly on the actual act of 'immersion' in VR and Transmedia, although this naturally plays an important part in the discussion, but instead its relationship to the experiences intended by film and TV professionals, wanting a more immersive experience for the types of content already produced. Narrative fiction springs readily to mind for example, or factual content that aims to bring the viewer 'closer' to the subject perhaps, or maybe interaction in TV entertainment formats. We can see the twin aims of contemporary TV and film in this approach; on the one hand to create more engaging experiences to reach new audiences, and on the other, potentially to find new ways to access audience analytic data to help reduce the risk of unpopularity inherent in creating new content. The reason this definition is important is that the immersive capacities of these technologies are currently being investigated widely in many fields; within VR alone for example, experiences such as the Galactica ride at UK theme park Alton Towers, political art pieces such as The Guardian's 6x9: Solitary Confinement piece or the iAnimal animal rights experience, and Royal London Hospital's live VR surgery transmission are all texts that stand apart from the subjects discussed in this paper. For example, in terms of the 'immersive' nature of the technology itself, the recent success of the Oxford University team using VR to treat patients suffering from social anxiety and paranoia offers evidence of the technology's capacity to partially 'fool the senses' in the manner seemingly expressed by Laramée above. This paper then will focus specifically on whether the introduction of these technologies into the content we normally associate with TV and film will actually create the desired immersive experiences that producers are looking for, and indeed whether 'immersion' should even be a goal of doing so.

It is perhaps no surprise that we can discuss the shift in terminology mentioned above as occurring over the last ten years, since it has now been a decade since Jenkins (2006) first coined the term 'Transmedia', and the concepts that it embodies - differing as they did at the time from the unsuccessful convergence strategy of '360' ('360 Commissioning', '360 Technologies') - have been gradually filtering into the way programmes and films are conceived, pitched, commissioned and produced since. It was in relation to Transmedia 
content and experiences that 'immersion' began to be used with frequency in industry debate and publications, and while of course the term was in-use prior to this to discuss more traditional film and television experiences, the implied meaning and use of the term in relation to Transmedia inferred something more, as we shall see. More recently again, the current race amongst various production companies and studios to harness the potential of Virtual Reality - especially coinciding as it does with the capacity to produce 'filmed' VR content in a meaningful way for the first time - has seen the idea of 'immersion' and pursuit of 'immersive content' come to the fore as both a self-evident goal, and a byword for new technological experiences. It is worth mentioning at this point that while we use the term Virtual Reality in relation to the 360-degree content being produced for TV and film, the correct definition of Virtual Reality is an experience similar to that newly offered by the HTC Vive, where users participate and interact with an experience. What we are concerned with currently in TV and film is simply 360-degree filmed or animated content in which the audience member has no participatory function other than to watch, either on a screen or via a headset. However, the industry has appropriated the 'VR' term to refer to this content, and for the sake of consistency this paper will do the same.

What is interesting about both Transmedia and VR is that their underlying principles are a lot less contemporary than some of their current film and television proponents seem ready to acknowledge; Virtual Reality has of course been in conceptual existence at least since the 1980s, and while Transmedia as a term is a $21^{\text {st }}$ Century concept, the idea of multi-form narratives and even the 'rabbit-hole' story experiences we associate with it could be argued to be traceable back to texts such as The Wizard of $O z$ in the early $20^{\text {th }}$ Century for example, or perhaps Japan's Media Mix from the 1950s and 1960s onwards. Indeed, given that both technologies bear more than a passing resemblance to ideas that existed first in the realms of science-fiction (for example, Phillip K. Dick's Eye in the Sky (1957) or The Electric Ant (1969) arguably predict such technologies with storylines involving computer-controlled realities) and there is of course a strong tradition of theorists discussing the potential debates surrounding technologies before they actually exist, as a result there is now a wealth of excellent predictive theory on both disciplines. Ryan for example noted in 2001 that "... since the idea of VR is very much a part of our cultural landscape, we don't have to wait [until the new century reaches adulthood] to explore the perspectives it opens on representation". In addition, the idea of immersion that has started to become associated with both Transmedia 
and VR has already been widely debated by ludologists writing about the games industry for many years, with perhaps the most traditional interpretation of the term - as outlined by Laramée above - arguably disproven on a number of occasions. Yet despite this, the many lessons learned by that industry and predicted by various theorists appear to have been either overlooked or bypassed by the contemporary film and TV industries in their approach to Transmedia and VR, an approach that this paper contends is erroneous and problematic, as we shall see.

To understand why this might be, we must first look at what is being referred to by the term 'immersion'. Farber's use above is just one example of the loosely-defined and interchangeable way that it is being introduced to contemporary TV discourse; both as a desirable outcome for programme-makers and audiences alike, and also as an achievable one through technology (the inference that moving content away from 'traditional flat screens' will make it more immersive). Moore's comment (above) in relation to VR for BBC Children's experiences being more 'immersive' is a similar case in point. Both examples illustrate the way the term is being regularly used in relation to TV content and audiences, and both appear to incorporate the term in a manner similar to Laramée's example.

One method of interpreting Laramée might be in an almost Cartesian sense, which at its most extreme perspective would share more than a passing resemblance to the central mechanism of classic 'solipsist' sci-fi narratives, such as perhaps The Matrix or Existenz. The notion that sensory input we experience from eyes and ears, and perhaps in the future from tactile and olfactory senses, might one day be so richly detailed and persuasive that we are no longer able to penetrate its artifice - we are sensorily displaced - is well-known, but also not especially credible as an explanation of his intention. A more sympathetic interpretation of the quote reads it as simply attempting to convey the form of immersion we are familiar with when we experience the more traditional 'displacement' effect of media texts, such as literature, radio, television and movies. As Ryan (2001) notes, the language we use to describe the process of reading a good book, as an example, is worthy of a novel itself.

The reader plunges under the sea (immersion), reaches a foreign land (transportation), is taken prisoner (being caught up in the story, being a captured audience) and loses contact with all other realities (being lost in a book). 
Interestingly, whether one takes the science-fiction interpretation of immersion, or the more traditional literary sense of the term as the flesh on the bones of Laramée's statement, both point to the idea of the audience member being removed from their understanding of space and time in the present moment, and being displaced elsewhere, what Salen and Zimmerman (2004) describe as the 'Immersive Fallacy'.

The immersive fallacy is the idea that the pleasure of a media experience lies in its ability to sensually transport the participant into an illusory, simulated reality. According to the immersive fallacy, this reality is so complete that ideally the frame falls away so that the player truly believes that he or she is part of an imaginary world.

It is perhaps understandable that this interpretation of Immersion would naturally dovetail with technologies such as VR and Transmedia; both are designed to place the audience member within the content, with VR removing the participant sensorily from their current environment, and Transmedia placing the audience member in a participatory role of decision-making and interaction with the narrative. We may even be able to state - in the case of VR at least - that the participant is immersed, at least in terms of sense-data, as in the case of the Oxford University 'paranoia' project mentioned above. However, in the sense that we are referring to as 'displacement immersion' and which is inferred by the quotes above, both technologies have an inherent contradiction that renders them unable to provide this type of content immersion for traditional film and TV experiences, such as drama or documentary pieces.

Salen and Zimmerman actually interrogate the same Laramée quote above as their example of the immersive fallacy, and in writing about the way immersion relates to computer games, offer their own reasons for the abandonment of the 'displacement' notion of immersion from a ludological perspective. For our purposes, another aspect of Laramée's quote is instructive in discussing the relationship between immersion and Transmedia/non-participatory VR in relation to TV/film content, and that is 'suspension of disbelief'. While not perhaps a universally accepted view, nevertheless suspension of disbelief still continues to be a tacitly acknowledged interpretation of the way in which audiences interact with especially fictional texts in film and television. 
Television entertainment involves the social convention of the "willing suspension of disbelief", in which we, for a brief time, agree to accept the characters portrayed onscreen as real human beings so that we can identify with them and experience their joys and sorrows. (Harris \& Sanborn, 2014)

Again I have focused on television particularly as in the UK this is an industry where there are significant efforts being made to understand and implement the technologies of Transmedia and VR, and also because the nature of television content is regularly long-form, meaning that the notion of suspension of disbelief on the part of television audiences can continue uninterrupted for months and years for the same characters and story-worlds, and even for decades in the case of certain well-known soap opera characters. Suspension of disbelief is therefore inherently linked with television and film in terms of the generally accepted understanding of the ways in which audiences interact with content, and it is therefore also understandable that film and TV professionals moving into Transmedia and VR content production will approach these new platforms from that same perspective. However, to do so is a fundamental mistake, as both traditional suspension of disbelief, and its thenassociated notion of 'displacement immersion' cannot effectively apply to either platform.

An examination of suspension of disbelief will reveal the problem, and for this we must needs move on from Coleridge's initial coining of the term in relation to 'poetic faith' in 1817 , turning instead to Holland and his continuing work on the psychology and psychoanalysis of suspension of disbelief as an act. In his early interpretation of the term, Holland (1967) discusses how a text must fulfil certain criteria in order to allow an audience to suspend disbelief, namely that in order to recognise that a text will provide us with an entertainment pleasure, we must be able to 'trust' it, and this trust comes from the recognised 'unreality' of the text.

We trust in works of art to give us pleasure, but it must be a pleasure from things merely imaginary. Should the pleasure seem to be a pleasure from real things, we no longer trust the work of art que work of art. 
In Salen and Zimmerman's point above, they mention the concept of the work providing the immersion as being framed - the 'frame falls away' - and this is closely related to Holland's interpretation of suspension of disbelief, as he suggests that in order for this trust to take place, and for this 'unreality' to be perceived, the text must be 'framed' away from reality, to be clearly positioned as an unreal and therefore trustworthy, pleasure-inducing artefact.

The conventions of art establish an isolation. We frame the picture, house it in a museum, surround it with "Do Not Touch" signs. Poems and cartoons are printed in such a way that we immediately recognise them as separate. Plays happen in special places - I remember one theatre where you had to cross water (a moat) to enter that half-magic world. Short stories and novels are often labelled as such - certainly a sentence or two tells us we are dealing with fiction, not "truth".

Holland's conclusion from this is that during suspension of disbelief, audiences are effectively able to disconnect the 'planning to act' function of the brain from the enjoyment of the text. He suggests an example of moviegoers recognising that they can enjoy the thrill of a scary film for example, without the need to fear for their own safety. Updating this theory with a neuro-psychoanalytic explanation in 2003, he suggests that suspension of disbelief has four parts:

1. we no longer perceive our bodies

2. we no longer perceive our environment

3. we no longer judge probability or reality-test

4. we respond emotionally to the fiction as though it were real

His conclusion is that in 'turning off' our 'desire to act' function, we effectively shut-down the prefrontal cortex of the brain responsible for our ability to 'plan to act' while the corticolimbic systems within our brains that are responsible for emotional response remain active. In order for this to take place, we must be assured that the world of the narrative is disconnected from the world outside of the text. This is to ensure that we do not attempt to act within the 'outside' world, based on stimulus from the text (such as experiencing genuine personal threat from a scary movie as-per the example above). This is the reason for the 'frame', to emphasise the unreality of the text perceived, allowing emotional response but not 
necessitating physical function. It is in this way that we can challenge one of the well-known criticisms of the suspension of disbelief theory; that extremely unlikely events such as Superman's capacity for flight are acceptable within a narrative, but his ability to disguise himself from co-workers simply by adopting a pair of glasses is not; the process of suspension of disbelief allows us to accept the unreal, but not the improbable, being as it is too closely related to our world in which we plan to act.

It is through this notion of the 'frame' that we begin to see the contradiction inherent in both Transmedia and VR experiences. In attempting to draw the participant 'closer' to the narrative, to remove the perceived barriers of mediation to create what is conceived as a more 'immersive' audience experience, we remove the signifiers of unreality from a text, and consequently our capacity to disconnect the 'planning to act' aspect of our experience in relation to the text is impaired. In principle, the more 'real' a text is designed to be, the less real is its perception and at the logical end of this argument, the hyper-awareness inherent in VR experiences and the participatory aspect of Transmedia - where decisions and interactions are necessary - means that our 'planning to act' function cannot be removed in either experience. In essence, in both Transmedia and VR, the 'frame' is incorporated within the media text as part of the experience, and for this reason it becomes harder to see the text as 'unreal', harder in-turn to disconnect the 'planning to act' function described, harder to experience a suspension of disbelief and therefore harder to achieve the type of immersive experience offered by Laramée; that which we have termed 'displacement immersion' where an audience of a media text forgets that they are being 'subjected to entertainment'. This then is the contradiction inherent in both technologies and the paradox of 'displacement' immersion simultaneously; the more one attempts to achieve this immersion, the less likely one is to do so.

There is also a contradiction inherent in this explanation however, which is of course Holland's assertion that we must be able to perceive the 'unreality' of a text in order to suspend disbelief, because our argument so far has suggested that we are unable to suspend disbelief in the case of VR and Transmedia experiences precisely because we perceive them as 'unreal'. The decision-making and participation in Transmedia, and the clearly mediated experience of VR - wearing a headset for example, the isolation of headphones, the technological issues of 'stitched' footage or low-resolution screens at such close proximity to 
the eyes - ensure that we are continually reminded that the text is false; a constructed narrative, a mediated documentary. And yet we are still unable to suspend disbelief. It is important here to remember our earlier distinction; that our discussions relate to the immersion within content, and not technological experiences. When we become 'immersed' in a novel, or in a TV show, or in Japanese Kabuki theatre perhaps, where the audience 'agrees not to see' the black-clad figures on stage holding scenery and props, we are aware of the 'rules' of mediation, and we are able to then put those to one side to simply enjoy the text itself (the performance, the story etc.). Holland's (2003) explanation is one of Habituation and he explains it with the analogy of wearing shoes:

Think about your shoes. You put your shoes on in the morning and for a few seconds you are aware of them. You can feel them on your feet. After a few seconds, you cease to be aware of them, and you don't become aware of your shoes again until you take them off at night - unless you get a blister or a pebble.

To continue Holland's analogy, by including the 'frame' within the experience, both Transmedia and VR technologies can effectively cause the 'blister or pebble' for the participant. Within an experience such as the use of VR to treat paranoia by Oxford University, or Al-Jazeera's excellent Pirate Fishing Transmedia journalism experience, this continual reinforcement of unreality may be ameliorated by the nature of the content in the sense that in both experiences, audiences aren't required to suspend disbelief in the traditional film and TV sense. But in those texts where suspension of disbelief would normally be needed, such as fiction or documentary, the continued inclusion of the 'frame' within the experience is problematic, as traditionally the frame is acknowledged and then habituated to. To complete the analysis, we might say that the perceived frame reinforces that the text is separate from reality, whereas the inclusion of the 'frame' in the experience - the 'blister or pebble' - reinforces only that the text is not reality.

This notion of the 'framed' artefact allows us to explain the immersion experienced in perceiving clearly non-real texts such as animation, black \& white films and even computer game experiences such as Tetris. The clear 'unreality' of the texts allows for a successful and willing suspension of disbelief to occur, as long as audiences can be habituated to the 'frame'. The interesting example here however is Tetris, which as a computer game has a clear 'planning to act' function fundamentally attached. Indeed, immersion is an idea that, as we 
have seen, has long been the subject of debate in ludological industries, and conclusions have been drawn that would certainly be of benefit to the emergent Transmedia and VR proponents in TV and film, as indeed with a reevaluation of the goal of immersion, it may still be achievable. Regarding Tetris for example, Salen \& Zimmerman (2004) quote Gorfinkel:

[...] representational strategies are conflated with the effect of immersion. Immersion itself is not tied to a replication or mimesis of reality. For example, one can get immersed in Tetris. Therefore, immersion into game play seems at least as important as immersion into a game's representational space. It seems that these components need to be separated to do justice and better understand how immersion, as a category of experience and perception, works.

Salen \& Zimmerman conclude that Gorfinkel's point suggests that immersion is not predicated on a representation of reality - a position they agree with - allowing discussions of immersion to move away from more traditional suspension of disbelief. While we have seen that suspension of disbelief by its very nature can accommodate 'unreal' representations such as black \& white cinema or animated content that only loosely resemble 'real life', nevertheless this is a valid criticism of our attempts to define immersion, as Gorfinkel's point about the 'immersive' properties of Tetris is certainly accurate. The rejection of 'displacement immersion' earlier was predicated on its fundamental link to suspension of disbelief, and the inherent removal of the 'planning to act' function according to Holland. Consequently, doing-away with suspension of disbelief from our definition of the term may potentially make it possible to achieve immersion in Transmedia and VR in the manner Laramée seems to suggest. However, we could argue that this condition of the definition is perhaps more applicable to the games industry - where the point was raised - than the experience of TV and film viewers venturing into VR and Transmedia. The reason is that by definition, gameplay has traditionally involved the introduction of a player's imagination into the process, in a way that TV and film experiences do differently and arguably inconsistently.

Clearly, many of the best and most engaging film and TV works rely on the capacity of suggestion to create the desired experience; such experiences certainly involve audience imagination, and to suggest otherwise is folly. However the introduction of imagination into gameplay can take far more complex forms; for example there isn't the same separation of 
artefact and imaginative process in TV and film that we can find in some games. Describing role-playing games for example, Brown (2012) observes:

In these kinds of games, the ludic framework generally requires basic representations of characters or items on its terms, so a sword may be represented as attack dice, or a player's character by a model on a hexagonal grid. However, most of the representational work of these games occurs in the player's imagination, and the business of playing tends to take place on an imaginative and discursive level separate to that of the tools used to simulate character interaction.

In this way, we can see the separation of gameplay experiences and that of other media texts; gameplay by definition requiring game players in order for the game to even exist. As Brown acknowledges:

Games need players, and this is one of the ways they are differentiated from the majority of other media experiences which require only audiences.

Leaving aside the participatory nature of Transmedia and VR for a moment - we shall return to it presently - film and television experiences are traditionally closer to that of 'art' than that of 'game', in that there is an inherent separation between text and audience. While games cannot exist without players, films arguably exist - in one interpretation at least - without audiences. This is separate from Holland's discussion of 'framing' art - "the altarpiece becomes art when it hangs in a museum rather than a church" (1967) - and simply an observation that a film or television programme could be said to exist independently of an audience, in the way that a game cannot. It is understandable therefore if film and television professionals moving into VR and Transmedia fields approach them from this perspective. However, to do so is an error as both Transmedia and VR texts, like games, are arguably both reliant on participation for their existence.

Within this fundamental understanding of both however lies the key to the capacity for immersion that both platforms do contain, and this can be found in revisiting Gorfinkel's quote above. While Salen \& Zimmerman rightly point out that part of the immersive experience of Tetris illustrates that immersion is not predicated on mimesis of 'reality', the 
deeper analysis of this separation concerns the notion that the representational experience and the participatory experience of the text are separate. Immersion cannot take place in the representational space of a text, but it can occur in the participatory space, and Gorfinkel's point is that the two are often conflated erroneously, leading to the conclusion that - as the more identifiable space perhaps - immersion is predicated on representation.

In a recent example, typical of this approach, Reilhac (2016) enthusiastically extols the virtues of VR experiences thus:

This incredibly powerful immersiveness of the VR experience triggers an equally powerful sense of presence for the viewer. When immersed in VR, we are no longer a spectator of a reflection of something happening far from us; we are in the moment, in that space with the people around us, we are part of what we see and hear.

And later:

We are immersed, present, feeling total empathy and passion in this experience. We can be involved; we can feel emotional depth like never before; we can engage and exchange; consider alternative points of view; we can experience diversity.

Reilhac appears throughout this article to be referring simultaneously to representation and participation interchangeably as the same experience - the VR experience we might call it and his definition of immersion seems also to relate simultaneously to the displacement of the senses, the mediated 'wonder' of the experience, and the participative, interactive capacity of the technology. It is perhaps difficult to disagree with this assessment in one sense - we have seen the capacity of the technology to 'fool the senses' in the Oxford University 'paranoia' project - but if we accept Gorfinkel's view that representation and participation are indeed separate - as the immersive capacity of something like Tetris would suggest - then what Reilhac is doing is experiencing the participative as the representative, and as such is not achieving immersion in the Laramée sense, but on the contrary, as a participant who is constantly hyper-aware that they are experiencing a mediated experience.

To build on this point, Salen \& Zimmerman's introduction of the notion of metacommunication to the experience of gameplay examines the integration of act and 
meaning, noting that when engaged in a game, players are entering into an experience in which the activity and the meaning of that activity (experienced and implied) are equally understood as part of the pre-agreed construct of the experience.

In the case of play, we know that metacommunication is always in operation. A teen kissing another teen in Spin the Bottle or a Gran Turismo player driving a virtual race car each understand that their play references different realities. But the very thing that makes their activity play is that they also know they are participating within a constructed reality [...]. It is possible to say that the players of a game are "immersed" - immersed in meaning. To play a game is to take part in a complex interplay of meaning. But this kind of immersion is quite different from the sensory transport promised by the immersive fallacy.

This notion is at the heart of the idea that immersion is possible in ludic experiences; immersion is caused by the act of engagement, the act of participatory gameplay. Reilhac's definition would perhaps have us believe that the Gran Turismo driver believes his race is real, or the 'Spin the Bottle' teens understand nothing implied by their actions. It is for this reason that the traditional debates surrounding ludonarrative dissonance took place, where the storyline of a game being at-odds with the gameplay created difficulties with immersion players finding that they couldn't 'get into' a game properly due to disconnect between the play and the plot structure - it was the gameplay that was creating the immersive experience and which was compromised by non-sympathetic storytelling.

If we return our focus to Transmedia and VR experiences for film and television therefore, we may be able to see how the lessons from ludic narratives can influence our approach to achieving immersion for ourselves. By their very nature, as we have seen, VR and Transmedia are participative; arguably they cannot exist without participants. So participation therefore becomes the goal of the immersive experience for both technologies. The idea of simply producing observable content in both formats in order to "make the content more immersive' is therefore problematic; the technology alone cannot achieve that goal. Instead, design based around the participative qualities and meaning of texts should be at the forefront of TV and film projects making the transition to these technologies. 
Up to this point, we have been discussing Transmedia and VR texts interchangeably because the focus was always on immersion as a concept. However, when we begin to discuss meaning and participation, this is where the two fundamentally different technologies must naturally diverge. How to create meaning and participation effectively across both disciplines is not a subject for this paper; all we have been concerned with here is identifying how the current goal of 'immersion' is unachievable, and replacing it with a version that is. However, we can discuss prevalent examples of both disciplines. In Transmedia for example, one of the most interesting recent instances of immersion is The Modular Body project. This is an online non-linear sci-fi story experience about using bio-printers to create organ modules (a 'brain module', a 'digestive module') to construct creatures. One such, 'Project Oscar', is a primitive and unnerving creation clearly designed to be an unsettling watch for audiences. The experience is clearly stated on the website and social media as being fictional, and there is no clear effort to deceive audiences. However, the short videos and text that form the 'objects' of the experience, as the BBC might call it, are believably real, with effective and sympathetic production values and visual effects, and the result has been a sharing through social media of single elements from the story experience, often without reference to the original site, by participants who believed that what they were sharing was real. This is the interesting immersive capacity of Transmedia storytelling; in this experience the story was not the non-linear narrative on the website, but the participative reality of audiences sharing and commenting on creepy videos, complete with philosophical and moral debates from those genuinely believing that their experience was real, and collectively creating the 'Modular Body story' as a real-time, real-world narrative of participation and meaning.

As one example of this within VR, one of my own experiences working with students at the University of Gloucestershire has been the delight and desire of participants experiencing VR content to explain to others what they are experiencing in real-time. Early experiments with participants experiencing mixed-media VR experiences for example, such as visuals from one source and audio - normally binaural recordings - from a separate source has created some interesting unique experiences for participants, most of whom mentioned afterward that their sense of immersion within the text was comparable to immersion in 'traditional' TV content, and yet part of this came from the desire to share verbally in real-time what they were experiencing. This could take the form of descriptions of the experience, explanation of emotional responses including the disconnect from those they were addressing or amusement 
at their unexpected reactions to the content. This paper will not look further at this research as our experiments in VR (our Dark Spaces VR experience is in production) and Transmedia (our Project Spider Transmedia experience is being developed) will be published more completely elsewhere.

Throughout this paper there has been no suggestion that producers of film and TV experiences should not be looking into VR and Transmedia content due to the immersion problem; on the contrary both disciplines offer extraordinary emerging opportunities for exciting and engaging new audience experiences and creative endeavours which will ultimately integrate very well into the way audiences interact with film and TV. Indeed, the purpose of this paper was to demonstrate that without interrogation and classification, the use of terms such as immersion could potentially slow and derail the progress of VR and Transmedia in these fields, simply because as we have seen, immersion is a goal, and the idea appears to be that the technology alone will provide that experience for audiences. Naturally, the one element omitted from this discussion is that which is almost self-evidently the most important; the strength and quality of the content itself, just as it always is in any film or TV text, because an engaging story is always an engaging story, independent of the technology used to tell it. But acknowledging that, this paper has hopefully demonstrated that when discussing immersion within a technological experience, we are meaning something quite different to when we are discussing immersion into the content played on that experience. This is because in order to achieve immersion in content, we must be able to suspend disbelief, even for factual content; we must be able to forget the mediation of the content and focus on it alone. Holland suggests that we do this by becoming habituated to a 'frame' that separates the content from the 'real world', and the suggestion made in this paper is that this is not achievable when the 'frame' is included within the experience, as then we cannot simply focus on the content alone. This is because unlike film and TV, VR and Transmedia arguably cannot exist independently, they require audiences for their existence. Immersion then takes place within these experiences in the participative space of the content, and not the representational space as in film and TV. To conclude therefore, immersion is possible within VR and Transmedia content, but it must be participative in some way; users must be able to become immersed in the participation and meaning of the text, and not simply observers of representational content in new environments. This is a view gaining increasing momentum within VR and Transmedia circles - Reilhac's February 2016 Indiewire article for 
example suggesting that VR experiences are not to be linked directly with film or gaming, because they are now strong enough on their own terms, is a case in point - although there is still a place for these technologies to integrate with film and TV, as long as it is understood that they cannot simply be an extension of an existing experience, but something new. 


\section{References}

Brown, DW. (2012) The suspension of disbelief in video games. (Doctoral Dissertation, Brunel University). Retrieved from http://bura.brunel.ac.uk/handle/2438/7457

Dick, PK. (1957) Eye in the Sky. New York. Ace Books.

Dick, PK. (1969) The Electric Ant. Fantasy and Science Fiction Magazine. October, 1969 ed.

Moore, R. quoted in Farber, A. (2016) Sky and BBC trial VR in bid to reach younger viewers. Broadcast Magazine. May 12 $2^{\text {th }}, 2016$ ed. Retrieved from http://www.broadcastnow.com

Farber, A. (2016) Virtual Reality: the 360-degree challenge. Broadcast Magazine. January $7^{\text {th }}$, 2016 ed. Retrieved from http://www.broadcastnow.co.uk

Gorfinkel, E. quoted in quoted in Salen, K \& Zimmerman, E. (2004) Rules of Play: Game Design Fundamentals. Cambridge, Massachusetts. MIT Press.

Harris, RJ. \& Sanborn, FW. (2014) A Cognitive Psychology of Mass Communication. $6^{\text {th }}$ ed. Abingdon, Oxon. Routledge.

Holland, N. (1967) The 'Willing Suspension of Disbelief' Revisited. The Centennial Review. Vol. 11. No. 1. Stable URL: http://www.jstor.org/stable/23737977

Holland, N. (2003) The Willing Suspension of Disbelief: A Neuro-Psychoanalytic View. PsyArt. January $22^{\text {nd }}, 2003$ ed. Retrieved from http://www.psyartjournal.com/article/show/n_hollandthe_willing_suspension_of_disbelief_a_ne

Jenkins, H. (2006) Convergence Culture: Where Old and New Media Collide. New York. New York University Press.

Laramée, FD. quoted in Salen, K \& Zimmerman, E. (2004) Rules of Play: Game Design Fundamentals. Cambridge, Massachusetts. MIT Press.

Reilhac, M. (2016) Why the Future of Virtual Reality Isn't Movies or Video Games. Indiewire. February $13^{\text {th }}, 2016$. Retrieved from http://www.indiewire.com/article/whythe-future-of-virtual-reality-isnt-movies-or-video-games-20160213

Reilhac, M. (2016) How Virtual Reality Will Make Us Re-Engage. Billionaire. May $11^{\text {th }}$, 2016. Retrieved from http://www.billionaire.com

Ryan, ML. (2001) Narrative as Virtual Reality: Immersion and Interactivity in Literature and Electronic Media. Baltimore, Maryland. The John Hopkins University Press.

Salen, K \& Zimmerman, E. (2004) Rules of Play: Game Design Fundamentals. Cambridge, Massachusetts. MIT Press. 


Online Journal of Communication and Media Technologies
Special Issue - September 2016

